\title{
Article
}

\section{Interface Direct Shear Tests on JEZ-1 Mars Regolith Simulant}

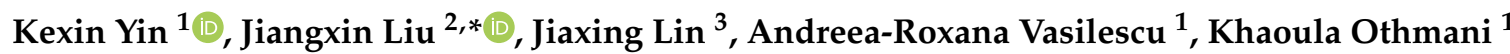 \\ and Eugenia Di Filippo ${ }^{1,4}$
}

1 Institut de Recherche en Génie Civil et Mécanique (GeM), Ecole Centrale de Nantes, UMR 6183 CNRS, 1 Rue de la Noë, CEDEX 3, 44321 Nantes, France; kexin.yin.research@gmail.com (K.Y.); rvasilescu@pintogc.com (A.-R.V.); khaoulaothmani13@gmail.com (K.O.); eugenia-difilippo@libero.it (E.D.F.)

2 Research Institute of Highway Ministry of Transport, Beijing 100088, China

3 Shandong Electrical Power Supply \& Transformation Engineering Co., Ltd., No. 1000 Meili Road, Huaiyin District, Jinan 250022, China; Jiaxing.lin007@hotmail.com

4 Department of Civil and Environmental Engineering, University of Perugia, 06125 Perugia, Italy

* Correspondence: jiangxin.liu10@gmail.com

check for updates

Citation: Yin, K.; Liu, J.; Lin, J.;

Vasilescu, A.-R.; Othmani, K.;

Di Filippo, E. Interface Direct Shear Tests on JEZ-1 Mars Regolith

Simulant. Appl. Sci. 2021, 11, 7052.

https://doi.org/10.3390/

app11157052

Academic Editor: Francesco Cafaro

Received: 2 July 2021

Accepted: 29 July 2021

Published: 30 July 2021

Publisher's Note: MDPI stays neutral with regard to jurisdictional claims in published maps and institutional affiliations.

Copyright: (c) 2021 by the authors. Licensee MDPI, Basel, Switzerland. This article is an open access article distributed under the terms and conditions of the Creative Commons Attribution (CC BY) license (https:// creativecommons.org/licenses/by/ $4.0 /)$.

\begin{abstract}
The mechanical behaviors of Martian regolith-structure interfaces are of great significance for the design of rover, development of excavation tools, and construction of infrastructure in Mars exploration. This paper presents an experimental investigation on the properties of a Martian regolith simulant (JEZ-1) through one-dimensional oedometer test, direct shear test, and interface direct shear tests between JEZ-1 and steel plates with different roughness. Oedometer result reveals that the compression and swelling indexes of the JEZ-1 are quite low, thus it is a less compressible and lower swelling soil. The cohesion and adhesion of JEZ-1 are lower than $5 \mathrm{kPa}$. The values of the internal friction angle range from $39.7^{\circ}$ to $40.6^{\circ}$, and the interface friction angles are $16.7^{\circ}$ to $36.2^{\circ}$ for the smooth and rough interface. Furthermore, the direct shear and interface direct shear results indicate that the interface friction angles are lower than the internal friction angles of JEZ-1 and increase close to the internal friction angles with increasing interface roughness.
\end{abstract}

Keywords: Mars Jezero Crater Delta simulant (JEZ-1); compressibility; direct shear test; soil-structure interface; friction angle

\section{Introduction}

The National Aeronautics and Space Administration (NASA) launched the Mars 2020 Perseverance Rover mission on 30 July 2020, the Perseverance Rover landed on Jezero Crater, Mars on 18th February 2021. The main job of Mars 2020 Perseverance Rover on Jezero Crater is seeking signs of ancient microbial life, and gathering samples of rock and regolith (i.e., broken rock and soil) for a possible return mission to Earth in the future for detailed analysis. The Perseverance rover is equipped with a drill to collect core samples of Martian rock and soil, then store them in sealed tubes to be brought back to Earth by a future mission.

Martian simulants are widely used for testing rovers and other instruments for Mars exploration, due to the fact that no rock or soil has been returned to Earth from Mars. Several typical Martian soil simulants have been designed and reported in the literature. For instance, Johnson Space Center JSC Mars-1 is the most remarkable Martian simulant [1]. Other important Mars simulants are Mojave Mars Simulant (MMS) [2] and its updated version MMS-1. However, the three simulants are no longer available outside of NASA [3]. Mars Global Simulant-1 (MGS-1) was developed by the University of Central Florida as an open mineralogical standard to precisely represent Martian global basaltic regolith [3]. Johnson Space Center-Rocknest (JSC-RN) is a new Martian simulant that was manufactured and utilized by NASA's Advanced Exploration Systems (AES) ISRU project, for experiments of water extraction from Martian soil [4]. However, these simulants reported above tend to be suitable for certain uses, but inappropriate for others [3]. 
This research mainly investigated the interface direct shear responses of a Martian simulant named JEZ-1, to provide the first insight into understanding the geotechnical characteristics of the Martian soil. It is a Jezero Crater simulant developed by the CLASS Exolith Lab at the University of Central Florida, in preparation for the Mars 2020 Perseverance Rover mission. JEZ-1 is specifically designed for the scientists and engineers looking to learn more about the landing site (Jezero Crater) of the Perseverance Rover and the scientific research that can be done there. The direct shear test is applicable to understand the mechanical behavior of Martian regolith, especially under different stress or strain conditions (e.g., large strains or critical state), according to [5-8]. The parameters of cohesion/adhesion and (interface) friction angle obtained from the direct shear test are fundamental information for the design of rover (e.g., landing systems and wheels) that is in contact with the Martian soil [7,9]. The test results in this paper will help pave the way for future human exploration of Mars.

\section{Materials}

\subsection{JEZ-1 Mars Regolith Simulant}

A Mars Jezero Crater Delta simulant JEZ-1 was selected for the research of the Martian regolith-structure interface. The Jezero Crater Delta Simulant (JEZ-1) was designed by the CLASS Exolith Lab at the University of Central Florida to simulate anticipated materials in the Jezero Crater Deltas that are now being investigated by the NASA Mars 2020 Perseverance Rover. In general, the mineralogy, chemistry, and grain size distribution of the regolith throughout the Jezero deltas are likely variable. The simulant is made up of MGS-1 mineralogy [3], smectite clay, Mg-carbonate, and additional olivine (Table 1), which have been detected in the Jezero Crater Delta deposits by orbital remote sensing. The other mineral components and major bulk elemental chemistry are presented in Tables 1 and 2, respectively.

Table 1. Mineralogy of JEZ-1 (results from Exolith Lab).

\begin{tabular}{cccc}
\hline Component & wt. $\%$ & Component & wt. $\%$ \\
\hline Olivine & 32.0 & Plagioclase & 16.0 \\
\hline Glass-rich basalt & 13.5 & Pyroxene & 12.0 \\
\hline Mg-carbonate & 11.0 & Smectite & 6.0 \\
\hline Mg-sulfate & 2.4 & Ferrihydrite & 2.1 \\
\hline Hydrated silica & 1.8 & Magnetite & 1.1 \\
\hline Anhydrite & 1.0 & Fe-carbonate & 0.8 \\
\hline Hematite & 0.3 & - & - \\
\hline
\end{tabular}

Table 2. Bulk major element chemistry of JEZ-1 (XRF results from Exolith Lab).

\begin{tabular}{cccc}
\hline Component & wt. $\%$ & Component & wt. $\%$ \\
\hline $\mathrm{SiO}_{2}$ & 44.2 & $\mathrm{TiO}_{2}$ & 0.2 \\
\hline $\mathrm{Al}_{2} \mathrm{O}_{3}$ & 11.3 & $\mathrm{Cr}_{2} \mathrm{O}_{3}$ & 0.3 \\
\hline $\mathrm{FeO}_{\mathrm{T}}$ & 9.5 & $\mathrm{MnO}$ & 0.1 \\
\hline $\mathrm{MgO}$ & 25.9 & $\mathrm{CaO}$ & 3.5 \\
\hline $\mathrm{Na}_{2} \mathrm{O}$ & 1.9 & $\mathrm{~K}_{2} \mathrm{O}$ & 0.3 \\
\hline $\mathrm{P}_{2} \mathrm{O}_{5}$ & 0.6 & $\mathrm{SO}_{3}$ & 2.1 \\
\hline
\end{tabular}

The primary shape and particle size of the simulant JEZ-1 can be seen from photograph in Figure 1a. The particle size ranges between $<0.04 \mu \mathrm{m}$ and $500 \mu \mathrm{m}$, which is composed of angular and sub-angular shapes from SEM images that are provided in Figure 1b,c. The grain size distribution curves of JEZ-1 and another two previous stimulants (i.e., JSC 
Mars-1 and MMS-1) are provided in Figure 2. From the grain size distribution test, the effective grain size $\left(d_{10}\right)$ of JEZ-1 is $4.9 \mu \mathrm{m}$ and the coefficient of uniformity $\left(C_{\mathrm{u}}\right)$ is equal to 14.3 , indicating that JEZ- 1 is a well-graded Martian simulant. The mean grain size $\left(d_{50}\right)$ of JEZ-1 is $57.2 \mu \mathrm{m}$, lower than the $d_{50}$ values of JSC Mars- $1(200 \mu \mathrm{m})$ and MMS-1 $(120 \mu \mathrm{m})$, according to the data from $[7,8]$. This highlights that JEZ-1 has finer grains than the other two simulants (i.e., JSC Mars-1 and MMS-1), in agreement with the fact that the Jezero Crater Delta contains clays, as revealed by the Mars Reconnaissance Orbiter's CRISM instrument. Clays only form in the presence of water, it is the reason why Jezero Crater Delta can provide a great place for the scientific goal of the Mars 2020 mission. It aims at seeking a potentially habitable environment that may possess preserved signs of ancient microbial life. For example, scientists have found that clays exist in the Mississippi River Delta on Earth, where microbial life has been found embedded in the rock. Moreover, from other laboratory test results, the uncompressed bulk density of JEZ-1 is $1.54 \mathrm{~g} / \mathrm{cm}^{3}$. The maximum void ratio $\left(e_{\max }\right)$ and minimum void ratio $\left(e_{\min }\right)$ are 0.798 and 0.381 , respectively.
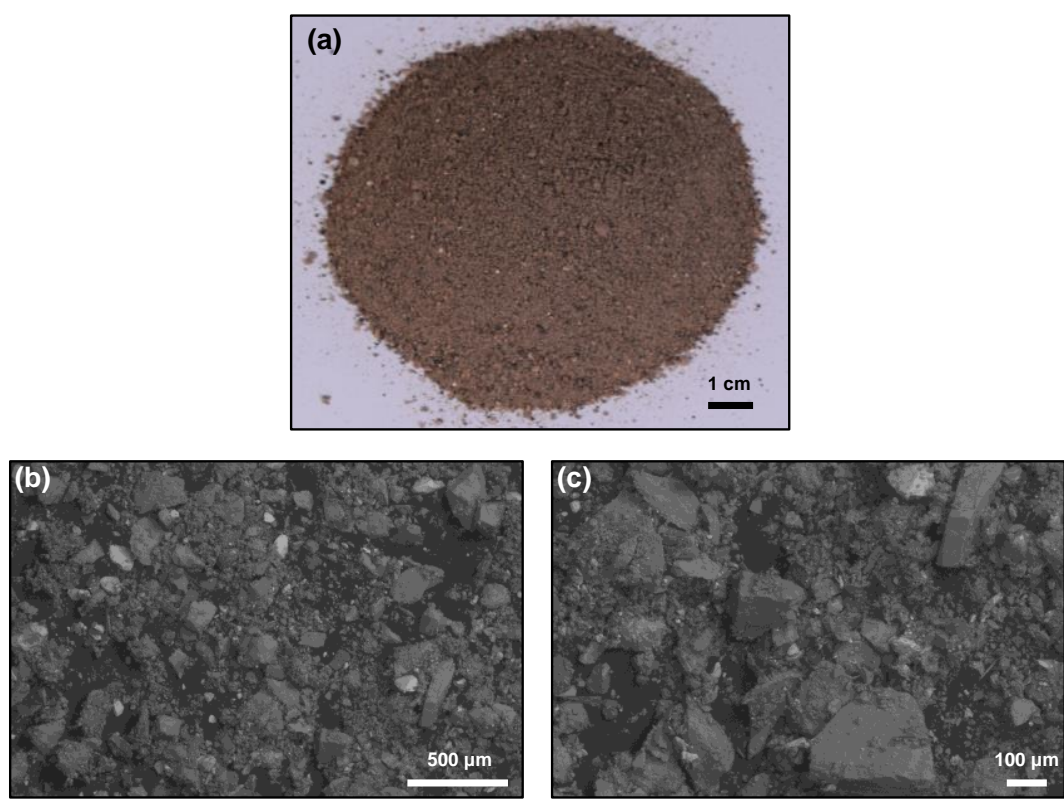

Figure 1. Photograph of Martian regolith simulant JEZ-1: (a) typical particles; and representative SEM images of JEZ-1 with magnification of: $(\mathbf{b}) \times 50,(\mathbf{c}) \times 100$.

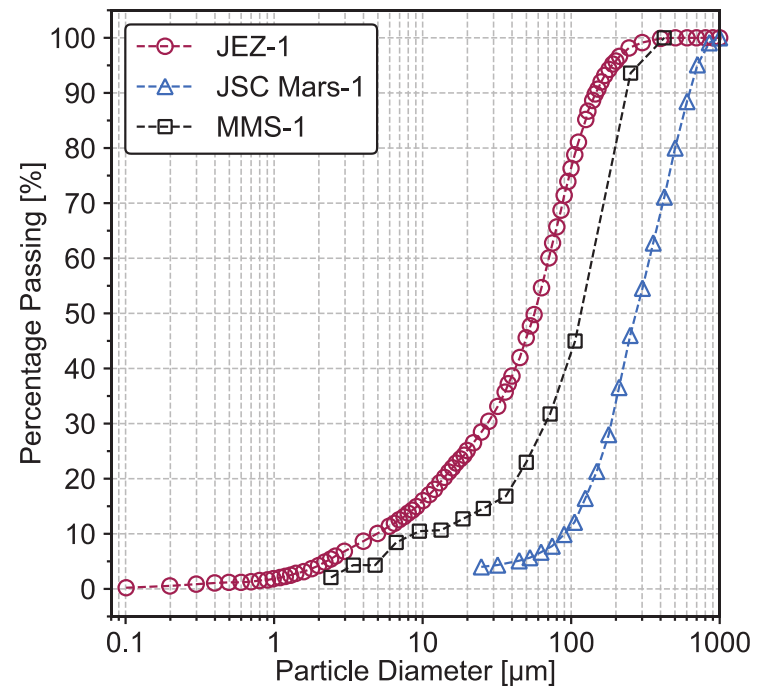

Figure 2. Grain size distribution curves of JEZ-1, JSC Mars-1 and MMS-1. 
Like other Martian soil simulants [4], the JEZ-1 represents an unconsolidated material as well, however, a more cohesive state can be obtained by compacting with various pressures.

\subsection{Steel Plate}

Two steel plates with different roughness (i.e., smooth and rough) are used as the structural material in the Martian simulant-structure interface, as presented in Figure 3. The size of the steel plates is $140 \mathrm{~mm} \times 100 \mathrm{~mm} \times 11 \mathrm{~mm}$. In this study, the rough steel plate is made by gluing a $2 \mathrm{~mm}$ thick layer of the mixture of epoxy resin and Fontainebleau sand ( $30 \mathrm{~g}$ of epoxy resin per $100 \mathrm{~g}$ of sand passing from the sieve of $0.63 \mathrm{~mm}$ ). While no sand is glued on the smooth plate.

The roughness of the steel plates is measured along with two directions of the plate surface (shear direction and perpendicular to the shear direction). The roughness parameters of arithmetic average height $\left(R_{\mathrm{a}}\right)$ and largest peak-to-valley height $\left(R_{\max }\right)$ are summarized in Table 3. The $R_{\mathrm{a}}$ values of the smooth and rough steel plates are $1.0 \mu \mathrm{m}$ and $45.1 \mu \mathrm{m}$, respectively, as shown in Table 3. The $R_{\max }$ values of the smooth and rough steel plates are $7.9 \mu \mathrm{m}$ and $277.0 \mu \mathrm{m}$, respectively (Table 3). Normalized roughness $\left(R_{\mathrm{n}}\right)$ is used for evaluating the interface roughness, in agreement with the literature [10-16]:

$$
R_{\mathrm{n}}=\frac{R_{\max }}{d_{50}}
$$

The $R_{\mathrm{n}}$ values of the smooth and rough steel plates are 0.14 and 4.86 (Table 3).

(a)

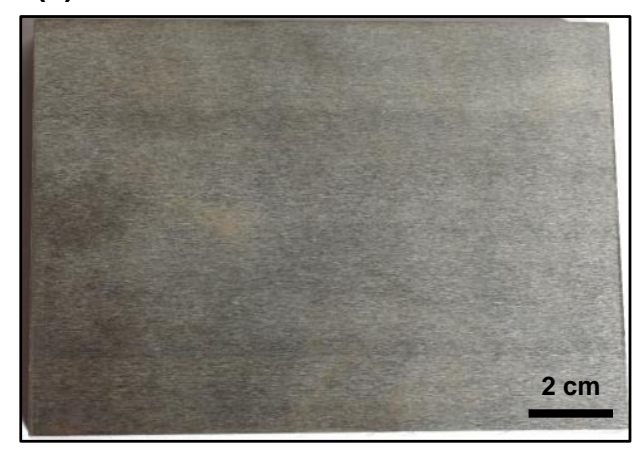

(b)

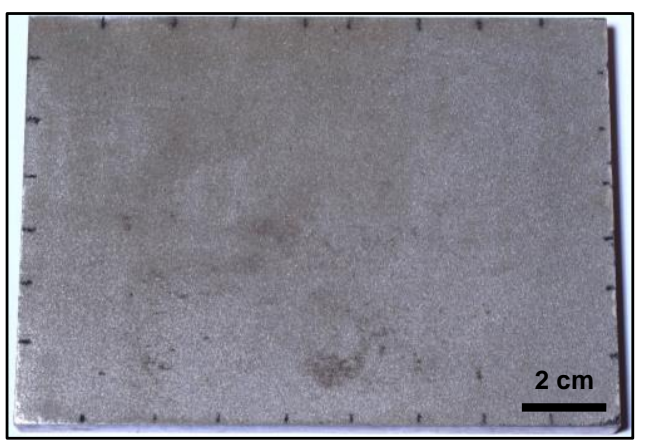

Figure 3. Steel plates for the interface direct shear test: (a) smooth and (b) rough surfaces.

Table 3. Roughness parameters of the steel plates.

\begin{tabular}{cccccc}
\hline $\begin{array}{c}\text { Plate } \\
\text { Number }\end{array}$ & $\boldsymbol{R}_{\mathbf{a}}(\mu \mathrm{m})$ & $\boldsymbol{R}_{\max }(\mu \mathrm{m})$ & $\boldsymbol{d}_{\mathbf{5 0}}(\mu \mathrm{m})$ & $\boldsymbol{R}_{\mathbf{n}}(-)$ & $\begin{array}{c}\text { Surface } \\
\text { Rough }\end{array}$ \\
\hline$\# 1$ & 1.0 & 7.9 & 57 & 0.14 & Smooth \\
\hline$\# 2$ & 45.1 & 277 & 57 & 4.86 & Rough \\
\hline
\end{tabular}

\section{Experimental Setup}

\subsection{Oedometer Test}

A one-dimensional oedometer test was performed on a dry JEZ-1 simulant, aiming to provide a first insight into its properties of compressibility. The effective vertical stress loading steps were $12.5 \mathrm{kPa}, 25 \mathrm{kPa}, 50 \mathrm{kPa}, 100 \mathrm{kPa}, 200 \mathrm{kPa}, 400 \mathrm{kPa}, 800 \mathrm{kPa}$, finally unloaded to $50 \mathrm{kPa}$, which is similar to $[15,17]$. The initial sample height and corresponding deformation were measured before and during the test, respectively.

\subsection{Interface Direct Shear Test}

In this paper, the mechanical behavior of the interface between JEZ-1 simulant and steel is investigated by a novel interface direct shear device (Figure 4a). This interface 
direct shear apparatus has the capability of conducting shear tests under different loading conditions. It was employed to perform experiments and to characterize the mechanical parameters of the soil-structure interface in the laboratory $[11,15,17-19]$. The interface direct shear box is divided into two parts, i.e., the upper and the bottom parts (Figure $4 \mathrm{~b}, \mathrm{c}$ ). The dimension of the upper part is $100 \mathrm{~mm} \times 100 \mathrm{~mm}$ and can contain a JEZ-1 sample with a maximum initial height of $50 \mathrm{~mm}$. The bottom part has a dimension of $140 \mathrm{~mm} \times 100 \mathrm{~mm} \times 11 \mathrm{~mm}$ in order to accommodate the steel plate. More details about the interface direct shear apparatus are available in [15].

(a)

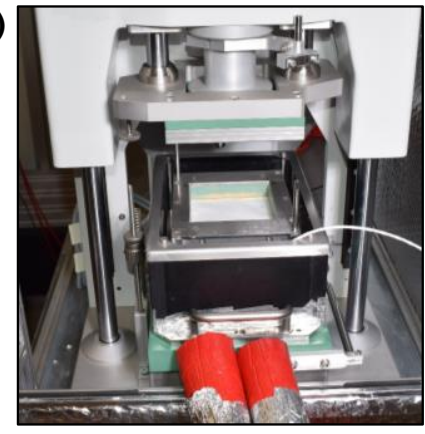

(b)

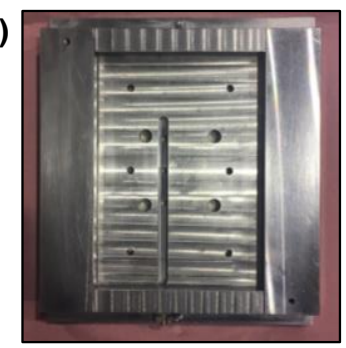

(c)

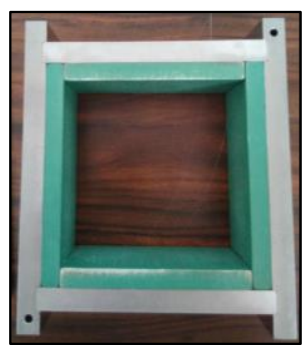

Figure 4. Interface direct shear apparatus: (a) loading frame, (b) bottom shear box and (c) upper shear box.

The experimental program presented in this section consisted of two phases: (1) direct shear, and (2) interface direct shear. Direct shear tests on the JEZ-1 simulant were firstly performed with the interface machine to get the shear results of soil-soil. Three direct shear tests were performed at normal stresses of 25,50 , and $75 \mathrm{kPa}$. The normal stresses for the interface direct shear tests with smooth and rough plates are 25, 50, 75, and $100 \mathrm{kPa}$. After the consolidation phase on the sample had been finished, a displacement-controlled shear was performed with a shearing rate of $0.5 \mathrm{~mm} / \mathrm{min}$ to a maximum horizontal displacement of $10 \mathrm{~mm}$.

The samples for the (interface) direct shear tests were prepared by the dry tamping method rather than other sample preparation techniques, such as wet tamping [20-22], slurry deposition $[15,17,23-28]$, due to the water was not considered in this paper. The average initial sample height for direct shear and interface direct tests are $31.59 \mathrm{~mm}$ and $27.58 \mathrm{~mm}$, respectively. Since very loose or very dense Martian regolith is not likely to encounter in the in-situ conditions, the average values of density $\left(\rho_{\mathrm{a}}\right)$ and relative density $\left(D_{\mathrm{r}}\right)$ are $1.84 \mathrm{~g} / \mathrm{cm}^{3}$ and $86.28 \%$, therefore all the samples for the two kinds of shear tests are dense $[6,8,29]$.

\section{Results}

\subsection{Oedometric Response}

Knowing the load-settlement relationship of the Martian simulant shed light on the design of a Rover or excavation tools [29]. So far, it is clear that there is a lack of data on the compression index $\left(C_{\mathrm{c}}\right)$ and swelling index $\left(C_{\mathrm{s}}\right)$ of Martian simulants in the literature. 
The void ratios as functions of the effective vertical stresses are plotted in Figure 5. From the straight-line part of the compressibility curve, the compression index $\left(C_{c}\right)$ is determined as:

$$
C_{c}=\frac{e_{1}-e_{2}}{\log \sigma_{v 2}^{\prime}-\log \sigma_{v 1}^{\prime}}
$$

where $e_{1}$ is the void ratio at effective vertical stresses of $\sigma_{v 1}^{\prime}$, and $e_{2}$ is the void ratio at effective vertical stresses of $\sigma^{\prime}{ }_{v 2}$. The swelling index $\left(C_{\mathrm{s}}\right)$ of the JEZ-1 simulant can be obtained from the data on the unloading line:

$$
C_{\mathrm{S}}=\frac{e_{1}-e_{2}}{\log \sigma_{v 2}^{\prime}-\log \sigma_{v 1}^{\prime}}
$$

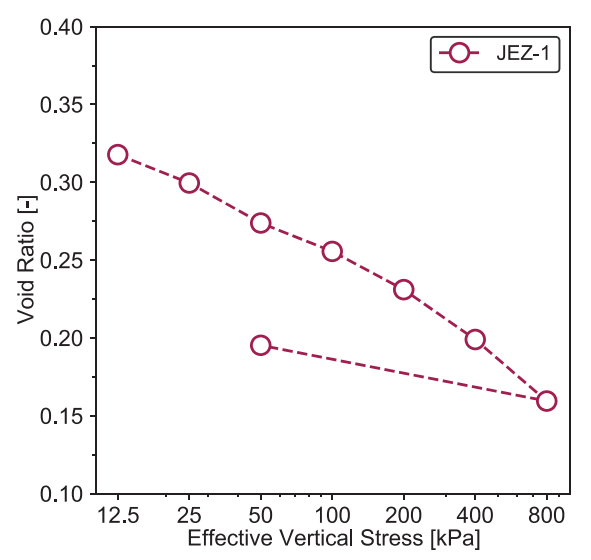

Figure 5. Void ratio as a function of the effective vertical stress.

The $C_{\mathrm{c}}$ is 0.131 and the $C_{\mathrm{s}}$ is 0.030 , which are calculated with the oedometric data of JEZ-1 in Figure 5. Both compression and swelling indexes of the JEZ-1 are quite low, indicating that it is a less compressible and lower swelling soil.

\subsection{Direct Shear Tests}

The direct shear tests were carried out on the dense specimens at different normal stresses (i.e., 25, 50, and $75 \mathrm{kPa}$ ), to find the cohesion and internal friction angle of JEZ-1. Figure 6a presents the shear stress responses of JEZ-1, direct shearing under a larger normal stress mobilizes larger shear stresses. The shear stress curves show a sharp increase then gradually go up to maximum finally to a constant volume state, due to the space between the upper $(100 \mathrm{~mm} \times 100 \mathrm{~mm})$ and the bottom $(140 \mathrm{~mm} \times 100 \mathrm{~mm})$ shear boxes, and the small holes on the bottom part of the shear box [15]. The JEZ-1 grains that go to the space and small holes mentioned above will result in a decrease on the sample density. Figure $6 \mathrm{~b}$ presents the normal strain as a function of shear displacement. The curves of normal strain show contraction firstly then dilation.

A simplified linear envelope is considered since the tests presented here were performed at neither quite low nor very high normal stresses, at which both the influence of dilation and particles crush were limited [7]. The linear-fitted envelopes are plotted in Figure 7. Peak and residual internal friction angles of the JEZ-1 are determined from the envelopes, as shown in Figure 7. JEZ-1 exhibits peak $\left(\varphi_{\text {peak }}\right)$ and residual $\left(\varphi_{\mathrm{cv}}\right)$ internal friction angles of $40.6^{\circ}$ and $39.7^{\circ}$, respectively. In addition, the peak $\left(c_{\text {peak }}\right)$ and residual $\left(c_{\mathrm{cV}}\right)$ cohesions are smaller than $4 \mathrm{kPa}$ (see Figure 7). 

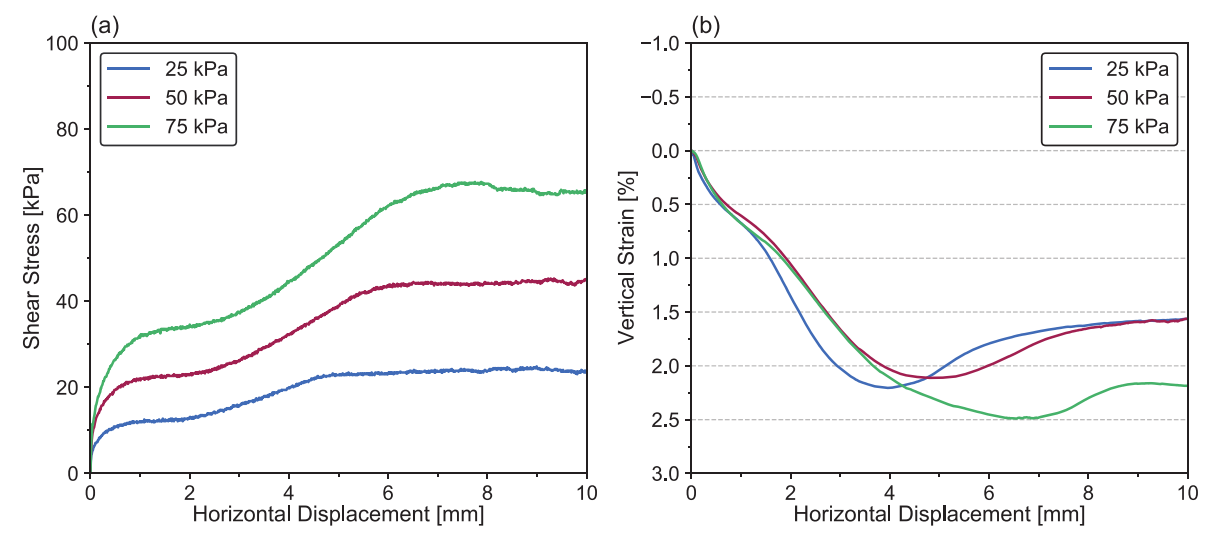

Figure 6. Direct shear test results of JEZ-1: (a) shear stress and (b) vertical strain as a function of horizontal displacement.

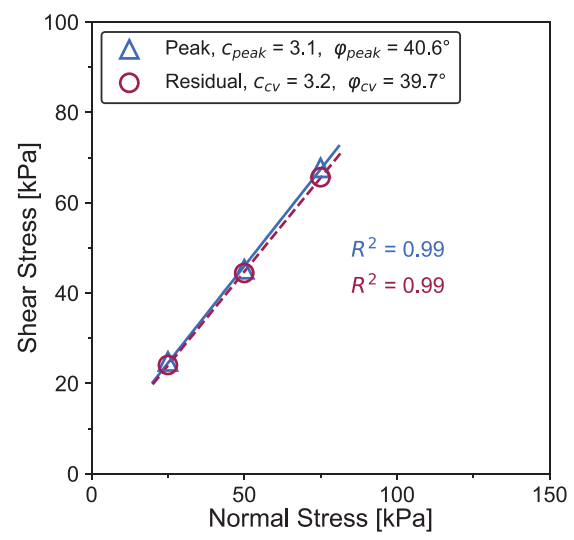

Figure 7. Peak and residual failure envelopes from direct shear tests of JEZ-1.

Table 4 presents the cohesion and internal friction angles derived from direct shear tests and compares these values with published results of other typical Martian simulants (JSC Mars-1 and MMS-1). JEZ-1 simulant is characterized with higher peak ( $3.1 \mathrm{kPa})$ and residual ( $3.2 \mathrm{kPa})$ cohesion than JSC Mars-1 (1.14 kPa and 0.87 kPa). However, MMS-1 has a peak cohesion of $15 \mathrm{kPa}$, which is considerably higher than the one of JEZ-1. The peak internal friction angle $\left(\varphi_{\text {peak }}=40.6^{\circ}\right)$ of JEZ-1 is lower than JSC Mars- $1\left(48.8^{\circ}\right)$ and MMS-1 $\left(46.0^{\circ}\right)$ with $8.2^{\circ}$ and $5.4^{\circ}$. While the $\varphi_{\mathrm{cv}}$ values between the three simulants are quite close (Table 4), with a slight difference range between $0.2^{\circ}$ and $1.4^{\circ}$.

Table 4. Cohesion and internal friction angle of Mars simulants.

\begin{tabular}{cccccc}
\hline $\begin{array}{c}\text { Name of Mars } \\
\text { Simulant }\end{array}$ & $\boldsymbol{c}_{\text {peak }}(\mathbf{k P a})$ & $\boldsymbol{c}_{\mathbf{c v}}(\mathbf{k P a})$ & $\boldsymbol{\varphi}_{\text {peak }}\left({ }^{\circ}\right)$ & $\boldsymbol{\varphi}_{\mathbf{c v}}\left({ }^{\circ}\right)$ & Reference \\
\hline JEZ-1 & 3.1 & 3.2 & 40.6 & 39.7 & This paper \\
\hline JSC-Mars & 1.14 & 0.87 & 48.8 & 41.1 & {$[7]$} \\
\hline MMS-1 & 15 & - & 46.0 & 39.9 & {$[8]$} \\
\hline
\end{tabular}

The cohesions of JEZ-1 are in agreement with the values obtained from in-situ tests from Spirit Rover $(1 \sim 15 \mathrm{kPa})$, and Opportunity Rover $(1 \sim 5 \mathrm{kPa})$, see [30,31]. With regard to the internal friction angles, JEZ-1 has much higher values than the in-situ results (about $20^{\circ}$ ) from both Spirit and Opportunity Rovers [30,31]. 


\subsection{Interface Direct Shear Response}

The interface direct shear characteristics are influenced by different factors such as sample density, shearing velocity, temperature, or interface roughness $[11,15,19,32,33]$. This paper investigated the mechanical response of the JEZ-1 simulant-steel interface under two roughness conditions: smooth and rough. The interface shearing results in terms of shear stress versus horizontal displacement are given in Figure 8. Under both smooth and rough steel surfaces, the mobilized shear stresses increase significantly with increasing normal stresses. Larger peak and residual shear stresses are mobilized with increasing surface roughness from smooth to rough at each normal stress (Figure 8). The peak and residual shear stresses are reached at larger horizontal displacement in the case of a rough surface rather than the smooth one.
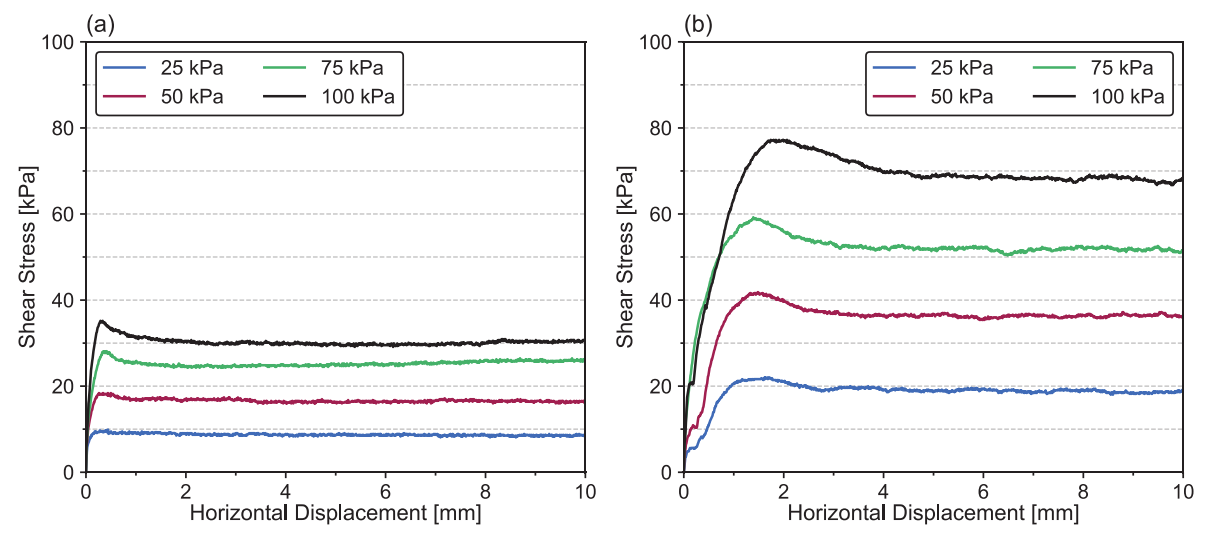

Figure 8. Shear stress as a function of horizontal displacement from interface direct shear test on JEZ-1-steel plate: (a) smooth and (b) rough surfaces.

Figure 9 compares the vertical strain as a function of normal stress and horizontal displacement during interface shearing. In the smooth interface test, the normal strain curves show contraction then slight dilation (Figure 9a). While for the rough interface, the curves experience contraction then larger dilation (Figure 9b).
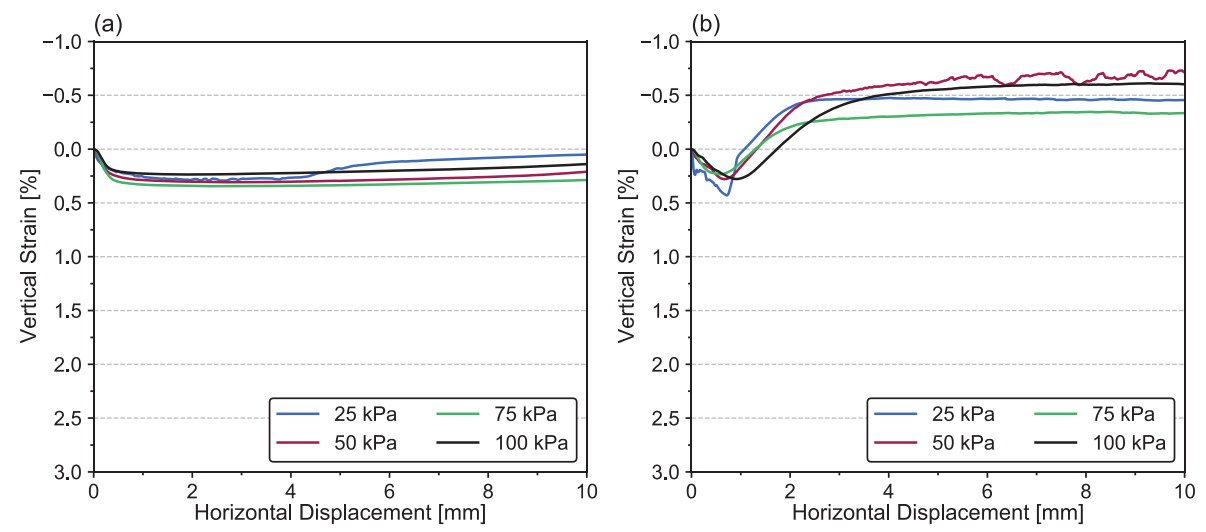

Figure 9. Vertical strain as a function of horizontal displacement from interface direct shear test on JEZ-1-steel plate: (a) smooth and (b) rough surfaces.

All the tests on JEZ-1 simulant-steel interface for the two considered roughness are summarized in the Mohr plane in Figure 10 and compared with the results of soil-soil. The peak and residual adhesions (i.e., $c_{\text {peak }}$ and $c_{\mathrm{cv}}$ ), as well as peak and residual interface friction angles (i.e., $\delta_{\text {peak }}$ and $\delta_{\mathrm{cv}}$ ) are obtained from the linear envelopes in Figure 10 . The $c_{\text {peak }}$ values of the smooth and rough interface are $1.5 \mathrm{kPa}$ and $4.3 \mathrm{kPa}$, and the $c_{\mathrm{cv}}$ values are $1.5 \mathrm{kPa}$ and $2.8 \mathrm{kPa}$, respectively. The $c_{\text {peak }}$ of the rough interface is somewhat higher than the one of internal $c_{\text {peak }}$, which is likely due to the contact between the JEZ-1 grains 
and the steel grooves that is caused by the sample preparation, however, the difference is only $1.2 \mathrm{kPa}$. All the interface $c_{\mathrm{cv}}$ values are lower than the cohesion of JEZ-1 $(3.2 \mathrm{kPa})$. The cohesion and adhesion of JEZ-1 in this paper are lower than $5 \mathrm{kPa}$, in accordance with the in-situ data from wheel trenches or wheel scuffs $[8,9]$.
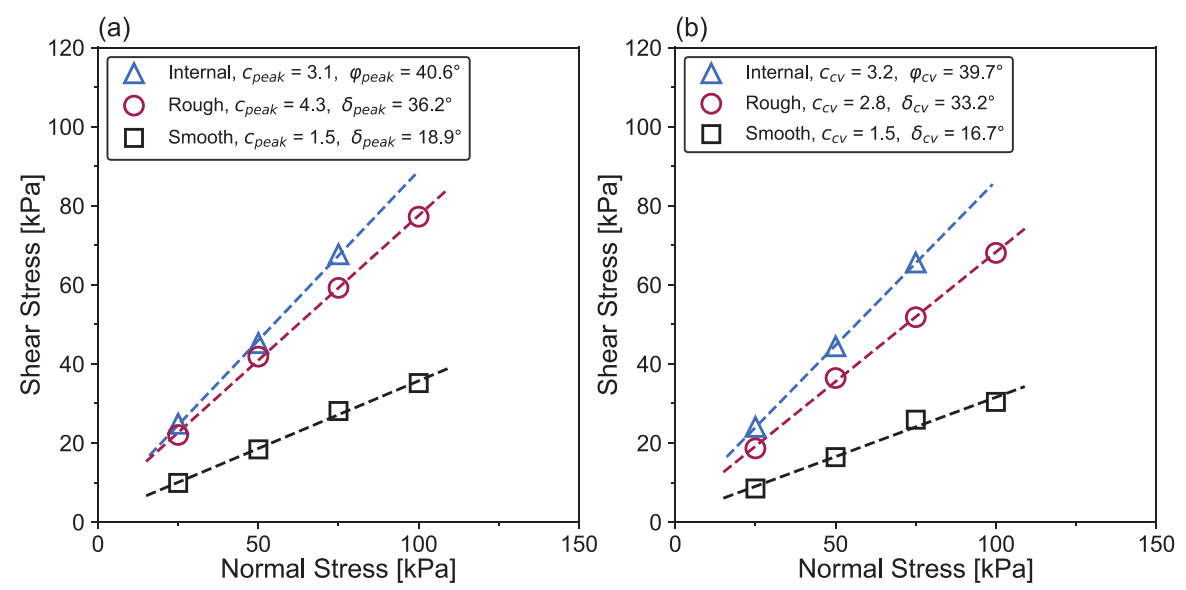

Figure 10. Summary of (a) peak and (b) residual failure envelopes for the three direct shear tests (soil-soil, smooth, and rough interfaces).

The peak interface friction angles $\left(\delta_{\text {peak }}\right)$ are $18.9^{\circ}$ and $36.2^{\circ}$, for the smooth and rough interfaces (Figure 10a). Figure 10b indicates that the residual interface friction angles of the smooth and rough interfaces, $\delta_{\mathrm{cv}}$, are $16.7^{\circ}$ and $33.2^{\circ}$, respectively. All $\delta_{\text {peak }}$ and $\delta_{\mathrm{cv}}$ values are lower than the $\varphi_{\text {peak }}$ and $\varphi_{\mathrm{cv}}$ of JEZ- 1 (i.e., $40.6^{\circ}$ and $39.7^{\circ}$ ), indicating that the shearing occurs in the interface zone rather than in the soil.

The peak and residual interface friction angles versus normalized interface roughness are plotted in Figure 11, though the data points are limited. The results indicate that the interface friction angles get close to the internal friction angles when shearing against rougher steel plate (Figure 11), in agreement with Earth soils-structure interface results [34,35].

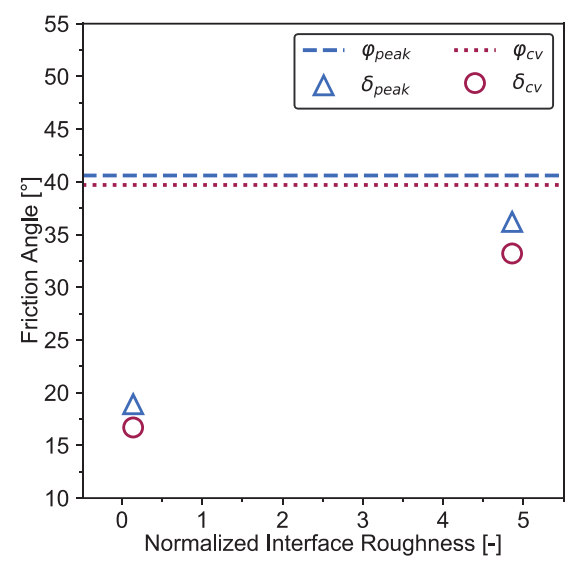

Figure 11. Interface friction angles as a function of normalized interface roughness, compared to internal friction angles of JEZ-1.

\section{Conclusions}

This paper aims at understanding the basic mechanical response of JEZ-1 Martian simulant, the characteristics of soil-soil and soil-steel interface have been investigated by direct shear tests in a laboratory. Based on the obtained results in this study, the main findings are concluded as follows: 
1. The compressibility and swelling index of JEZ-1 are quite low;

2. Both the peak and residual cohesion of JEZ- 1 are $<4 \mathrm{kPa}$. The peak $\left(\varphi_{\text {peak }}\right)$ and critical $\left(\varphi_{\mathrm{cv}}\right)$ internal friction angles are $40.6^{\circ}$ and $39.7^{\circ}$, respectively;

3. The adhesion of the interface between JEZ-1 and smooth/rough steel are lower than $5 \mathrm{kPa}$;

4. The peak interface friction angles $\left(\delta_{\text {peak }}\right)$ are $18.9^{\circ}$ and $36.2^{\circ}$, and the residual interface friction angles $\left(\delta_{\mathrm{cv}}\right)$ are $16.7^{\circ}$ and $33.2^{\circ}$, respectively, for the smooth and rough interfaces;

5. The interface friction angles $(\delta)$ are lower than the internal friction angles $(\varphi)$ of JEZ-1. The $\delta$ gets close to the $\varphi$ when increasing the interface roughness.

The interface results can provide information on Mars rover design, excavation tool determination as well as infrastructure development. Moreover, in the future, the interface results should be compared to the in-situ values of Jezero Crater Delta that are obtained by the Perseverance Rover. More geotechnical properties of the JEZ-1 Martian simulant need to be further investigated thoroughly.

Author Contributions: Conceptualization, methodology, data curation, writing-original draft preparation, K.Y. and J.L. (Jiaxing Lin); formal analysis, J.L. (Jiangxin Liu) and K.Y.; writing-review and editing, J.L. (Jiangxin Liu), J.L. (Jiaxing Lin), A.-R.V., K.O. and E.D.F.; All authors have read and agreed to the published version of the manuscript.

Funding: This research was funded by Research Institute of Highway Ministry of Transport.

Institutional Review Board Statement: Not applicable.

Informed Consent Statement: Not applicable.

Data Availability Statement: All data generated or used during the study appear in the submitted article.

Acknowledgments: The authors gratefully acknowledge Kevin Cannon, Jillian Gloria and Zoe Landsman for their important help.

Conflicts of Interest: The authors declare that they have no conflict of interest.

\section{References}

1. Allen, C.C.; Morris, R.V.; Jager, K.M.; Golden, D.; Lindstrom, D.J;; Lindstrom, M.M.; Lockwood, J.P. Martian regolith simulant JSC Mars-1. In Proceedings of the Lunar and Planetary Science Conference, Houston, TX, USA, 16-20 March 1998; p. 1690.

2. Peters, G.H.; Abbey, W.; Bearman, G.H.; Mungas, G.S.; Smith, J.A.; Anderson, R.C.; Douglas, S.; Beegle, L.W. Mojave Mars simulant-Characterization of a new geologic Mars analog. Icarus 2008, 197, 470-479. [CrossRef]

3. Cannon, K.M.; Britt, D.T.; Smith, T.M.; Fritsche, R.F.; Batcheldor, D. Mars global simulant MGS-1: A Rocknest-based open standard for basaltic martian regolith simulants. Icarus 2019, 317, 470-478. [CrossRef]

4. Clark, J.; Archer, P.; Gruener, J.; Ming, D.; Tu, V.; Niles, P.; Mertzman, S. JSC-Rocknest: A large-scale Mojave Mars Simulant (MMS) based soil simulant for in-situ resource utilization water-extraction studies. Icarus 2020, 351, 113936. [CrossRef]

5. Perko, H.A.; Nelson, J.D.; Green, J.R. Mars soil mechanical properties and suitability of Mars soil simulants. J. Aerosp. Eng. 2006, 19, 169-176. [CrossRef]

6. Iai, M.; Luna, R. Direct shear tests on JSC-1A lunar regolith simulant. J. Aerosp. Eng. 2011, 24, 433-441. [CrossRef]

7. David Frost, J.; Martinez, A. Interface Shear Response of JSC-1A, GRC-3, and JSC-Mars1 Regolith Simulants. J. Aerosp. Eng. 2018, 31, 04018003. [CrossRef]

8. Fujikawa, T.; Newson, T.; Ahmed, A.; Safdar, M. Assessment of the Geo-Mechanical Properties of Mojave Mars Simulant-1 (MMS-1) Soil. In Proceedings of the Geotechnical Engineering in the XXI Century: Lessons Learned and Future Challenges: Proceedings of the XVI Pan-American Conference on Soil Mechanics and Geotechnical Engineering (XVI PCSMGE), Cancun, Mexico, 17-20 November 2019; p. 268.

9. Sullivan, R.; Anderson, R.; Biesiadecki, J.; Bond, T.; Stewart, H. Cohesions and friction angles of Martian regolith from MER wheel trenches and wheel scuffs. In Proceedings of the Lunar and Planetary Science Conference, Woodlands, TX, USA, 1-5 March 2010; p. 1879.

10. Uesugi, M.; Kishida, H. Frictional resistance at yield between dry sand and mild steel. Soils Found. 1986, 26, 139-149. [CrossRef]

11. Vasilescu, A.-R. Design and Execution of Energy Piles: Validation by In-Situ and Laboratory Experiments. Ph.D. Thesis, École centrale de Nantes, Nantes, France, 2019.

12. Maghsoodi, S.; Cuisinier, O.; Masrouri, F. Thermo-mechanical behaviour of clay-structure interface. In Proceedings of the E3S Web of Conferences, Glasgow, UK, 25 June 2019; p. 10002. 
13. Maghsoodi, S.; Cuisinier, O.; Masrouri, F. Comportement thermo-mécanique de l'interface sable-structure. In Proceedings of the 17th European Conference on Soil Mechanics and Geotechnical Engineering, Reykjavík, Iceland, 1-6 September 2019.

14. Maghsoodi, S. Thermo-Mechanical Behavior of Soil-Structure Interface under Monotonic and Cyclic Loads in the Context of Energy Geostructures. Ph.D. Thesis, Université de Lorraine, Nancy, France, 2020.

15. Yin, K. Influence of Clay Fraction on the Mechanical Behavior of a Soil-Concrete Interface. Ph.D. Thesis, École Centrale de Nantes, Nantes, France, 2021.

16. $\mathrm{Hu}, \mathrm{L} . ; \mathrm{Pu}, \mathrm{J}$. Testing and modeling of soil-structure interface. J. Geotech. Geoenviron. Eng. 2004, 130, 851-860. [CrossRef]

17. Yin, K.; Liu, J.; Vasilescu, A.-R.; Di Filippo, E.; Othmani, K. A Procedure to Prepare Sand-Clay Mixture Samples for Soil-Structure Interface Direct Shear Tests. Appl. Sci. 2021, 11, 5337. [CrossRef]

18. Vasilescu, A.R.; Fauchille, A.-L.; Dano, C.; Kotronis, P.; Manirakiza, R.; Gotteland, P. Impact of temperature cycles at soil-concrete interface for energy piles. In Proceedings of the International Symposium on Energy Geotechnics, Lausanne, Switzerland, 25-28 September 2018; pp. 35-42.

19. Vasilescu, R.; Yin, K.; Fauchille, A.-L.; Kotronis, P.; Dano, C.; Manirakiza, R.; Gotteland, P. Influence of thermal cycles on the deformation of soil-pile interface in energy piles. In Proceedings of the E3S Web of Conferences, Glasgow, UK, 25 June 2019; p. 13004.

20. Vaid, Y.P.; Sivathayalan, S.; Stedman, D. Influence of specimen-reconstituting method on the undrained response of sand. Geotech. Test. J. 1999, 22, 187-195.

21. Sze, H.; Yang, J. Failure modes of sand in undrained cyclic loading: Impact of sample preparation. J. Geotech. Geoenviron. Eng. 2014, 140, 152-169. [CrossRef]

22. Raghunandan, M.; Juneja, A.; Hsiung, B. Preparation of reconstituted sand samples in the laboratory. Int. J. Geotech. Eng. 2012, 6, 125-131. [CrossRef]

23. Kuerbis, R.; Vaid, Y. Sand sample preparation-the slurry deposition method. Soils Found. 1988, 28, 107-118. [CrossRef]

24. Wang, S.; Luna, R.; Stephenson, R.W. A slurry consolidation approach to reconstitute low-plasticity silt specimens for laboratory triaxial testing. Geotech. Test. J. 2011, 34, 288-296.

25. Bendahmane, F.; Marot, D.; Alexis, A. Experimental parametric study of suffusion and backward erosion. J. Geotech. Geoenviron. Eng. 2008, 134, 57-67. [CrossRef]

26. Krage, C.P.; Price, A.B.; Lukas, W.G.; DeJong, J.T.; DeGroot, D.J.; Boulanger, R.W. Slurry Deposition Method of Low-Plasticity Intermediate Soils for Laboratory Element Testing. Geotech. Test. J. 2020, 43, 1269-1285. [CrossRef]

27. Yin, K.; Fauchille, A.-L.; Othmani, K.; Sciarra, G.; Kotronis, P.; Benoit, Y.; Bertrand, F.; Branchu, S. Influence of sample preparation on the multi scale structure of sand-clay mixtures. In Proceedings of the E3S Web of Conferences, Glasgow, UK, 25 June 2019; p. 01007.

28. Maghsoodi, S.; Cuisinier, O.; Masrouri, F. Thermal effects on one-way cyclic behaviour of clay-structure interface. In Proceedings of the E3S Web of Conferences, La Jolla, CA, USA, 18 November 2020; p. 05001.

29. Zeng, X.; He, C.; Oravec, H.; Wilkinson, A.; Agui, J.; Asnani, V. Geotechnical properties of JSC-1A lunar soil simulant. J. Aerosp. Eng. 2010, 23, 111-116. [CrossRef]

30. Arvidson, R.E.; Anderson, R.; Bartlett, P.; Bell, J.; Blaney, D.; Christensen, P.R.; Chu, P.; Crumpler, L.; Davis, K.; Ehlmann, B. Localization and physical properties experiments conducted by Spirit at Gusev Crater. Science 2004, 305, 821-824. [CrossRef] [PubMed]

31. Arvidson, R.; Anderson, R.; Bartlett, P.; Bell, J.; Christensen, P.; Chu, P.; Davis, K.; Ehlmann, B.; Golombek, M.; Gorevan, S. Localization and physical property experiments conducted by Opportunity at Meridiani Planum. Science 2004, 306, 1730-1733. [CrossRef] [PubMed]

32. Pra-ai, S. Behaviour of soil-structure interfaces subjected to a large number of cycles. Application to Piles. Ph.D. Thesis, Université de Grenoble, Grenoble, France, 2013.

33. Martinez, A.; Stutz, H.H. Rate effects on the interface shear behaviour of normally and overconsolidated clay. Géotechnique 2019, 69, 801-815. [CrossRef]

34. Tsubakihara, Y.; Kishida, H.; Nishiyama, T. Friction between cohesive soils and steel. Soils Found. 1993, 33, 145-156. [CrossRef]

35. Chen, X.; Zhang, J.; Xiao, Y.; Li, J. Effect of roughness on shear behavior of red clay-concrete interface in large-scale direct shear tests. Can. Geotech. J. 2015, 52, 1122-1135. [CrossRef] 